\title{
Testing and modeling dowel and catenary action in rebars crossing shear joints in RC
}

\author{
Sørensen, Jesper Harrild; Hoang, Linh Cao; Olesen, John Forbes; Fischer, Gregor
}

\section{Published in:}

Engineering Structures

Link to article, DOI:

10.1016/j.engstruct.2017.05.020

Publication date:

2017

Document Version

Peer reviewed version

Link back to DTU Orbit

Citation (APA):

Sørensen, J. H., Hoang, L. C., Olesen, J. F., \& Fischer, G. (2017). Testing and modeling dowel and catenary action in rebars crossing shear joints in RC. Engineering Structures, 145, 234-245.

https://doi.org/10.1016/j.engstruct.2017.05.020

\section{General rights}

Copyright and moral rights for the publications made accessible in the public portal are retained by the authors and/or other copyright owners and it is a condition of accessing publications that users recognise and abide by the legal requirements associated with these rights.

- Users may download and print one copy of any publication from the public portal for the purpose of private study or research.

- You may not further distribute the material or use it for any profit-making activity or commercial gain

- You may freely distribute the URL identifying the publication in the public portal 


\title{
Test and Modeling of Dowel and Catenary Action in Rebars Crossing Shear Joints in RC
}

\author{
Jesper H. Sørensen, Linh C. Hoang, John F. Olesen, Gregor Fischer \\ Technical University of Denmark, Department of Civil Engineering, Brovej, Bygning 118, \\ 2800 Kgs. Lyngby, Denmark
}

\begin{abstract}
This paper presents a detailed study of the shear behavior of two-sided dowel joints, which includes initiation of dowel action at small shear displacements and development of full catenary action in the reinforcement at large displacements. In addition to experimental results, the paper also presents a simple, second order plasticity model to describe the non-linear regime of the load-displacement relationship. In the model, kinematic relations and the normality condition of plastic theory are utilized to establish a unique link between the imposed shear displacement and combinations of moment and tension that develop in the rebar(s) crossing the joint. Interface friction is included in a consistent manner based on clamping stresses induced by the tension of the rebar(s). Comparison of experimental results with the model predictions shows satisfactory agreement. The model has, due to its simplicity, potential for practical applications related to assessment of structural robustness, where estimation of the available energy (area below load-displacement curve) is important.

Keywords: Dowel Action, Catenary Action, Concrete Plasticity, Second Order Modeling
\end{abstract}

\section{Introduction}

Dowel action in reinforcing bars is a well-known phenomenon which can be utilized as load carrying mechanism in structural concrete. Inclusion of dowel action in design is primarily relevant for problems that involve transfer of shear 
through casting joints and connections, see e.g. fib Bulletin 43 [1].

Pure dowel action is experimentally most clearly observed when a rebar has part of its length embedded in a large block of concrete while being loaded by a transverse force at the concrete surface. In most practical cases, the load carrying capacity will be governed be development of a plastic hinge in the rebar and by local crushing of the concrete. The first attempt to study this basic problem (which in the following will be termed 'one-sided dowel action') was carried out by Friberg [2] who modeled the dowel as a linear elastic beam transversely supported on elastic springs. Many researchers have since adopted this approach to model the load-displacement response of the dowel [3-10]. However, the obvious shortcoming of this approach is the fact that it is a linear elastic model. Some attempts have therefore been made to adjust the transverse spring stiffness $[11,12]$ and others again have empirically suggested a gradual change of stiffness to fit the non-linear test results [4-6].

Due to the non-linear material behavior, a model based on the theory of plasticity seems more appropriate to describe dowel action at the ultimate limit state. Such a model was first developed for one-sided dowel action by Rasmussen [13], who assumed crushing of concrete simultaneously with yielding of the reinforcement. In contrast to the basic problem studied by Rasmussen, Figure 1 schematically illustrates a so-called two-sided dowel joint, where the rebar is fully embedded in concrete on both sides of the casting joint. In this case, pure dowel action (represented by rotation, $\theta$, in the plastic hinges) is only the first phase of the load transfer mechanism of the joint. When the shear displacement in the joint, $u$, increases, the dowel action will gradually be accompanied by axial tension (represented by elongation, $\Delta$, in the plastic hinges). The load transfer mechanism is in this phase a combination of the two actions. At the final stage, dowel action may be completely replaced by axial tension, i.e. the load may be carried by pure catenary action in the rebar. Development of full catenary action requires relatively large shear displacements. For this reason, this effect is seldom utilized in the ultimate design of structural joints even though the load related to pure catenary action is usually higher than that 
corresponding to pure dowel action. However, for assessment of structural robustness as well as verification of structural performance under accidental load cases, catenary action may play an important role, not only for the behavior of shear joints but also when considering the behavior of slabs after initial bending and/or punching failure (Refs. [14-20]).

[Figure 1 about here.]

Several authors have recognized that for two-sided joints, the development of axial tension reduces the bending capacity of the dowel. In order to account for this reduction, a criterion for the combination of axial tension and bending is needed [21-25]. Basically, this criterion is the same as the MN-interaction diagram for the rebar cross section. The real challenge here is to establish a unique link between the shear displacement, $u$, and the points on the MN-interaction diagram. In the literature, this link is often established on a more or less empirical basis, e.g. based on experimental measurements of the axial tension in the rebar.

This paper presents an investigation into the behavior of two-sided dowel joints (i.e. rebars crossing an interface between concretes cast at different times), exposed to large shear displacements. The investigation covers both an experimental program as well as a theoretical study. Some few initial tests as well as basic ideas have been presented in a previous work-in-progress paper (Ref. $[26]$ ). One of the focus points of the experimental program has been to study the efficiency of rebar groups in comparison with single dowel behavior. This is relevant for practical applications because rebars crossing casting joints between precast concrete elements are often lumped in groups, e.g. in the form of overlapping U-bars. Furthermore, in addition to tests of the classical concreteto-concrete interface, the program also includes concrete-to-mortar interfaces. Tests of such combinations have, to the best knowledge of the authors, not been published before. The combinations are nevertheless important in practice, for instance when dealing with shear connections between precast concrete wall elements, which are often grouted with mortar. 
The experimental results have been used to calibrate and verify a theoretical model of the load-displacement response of two-sided dowel joints. The primary motivation for developing such a model is to provide a more accurate calculation of the displacement dependent resistance of shear joints under e.g. accidental load cases, as this information may facilitate an estimate of the overall robustness for the structural system. The model is based on a second order rigid-plastic approach, where change of structural geometry has to be considered in order to correctly model the response at large shear displacements. The adopted approach differs from most of the previous works on this topic and has the advantage of being able to provide a simple and unique link between the relative displacement in the joint and the MN-interaction diagram for the rebar cross section. The link is established by combining the normality condition of plastic theory with the kinematical conditions of the dowel. As will be shown, the link eventually also allows for inclusion of interface friction in a consistent manner.

\section{Experimental Program}

\subsection{Material Properties and Test Setup}

The experimental program was designed to examine the development of dowel and catenary action in rebars crossing an interface loaded in pure shear. For this purpose, push-off tests were carried out on specimens with one single rebar, two rebars and four rebars (i.e. $n=1,2$ or 4 ) crossing the casting joint. In most cases, three replicates of the same layout were successfully tested. The general specimen layout is shown in Figure 2. The rebars were placed symmetrically about the principal axis of the specimen cross section. In the case of $n=2$ and $n=4$, the rebars were placed with a mutual distance of $42 \mathrm{~mm}$. The shear load was applied in the direction of the $z$-axis shown in Figure 2. Specifications and material properties have been summarized in Table 1. As indicated in Figure 2, confinement reinforcement in the form of rectangular stirrups was used to prevent premature splitting failure of the concrete block. The rebars crossing 
the casting joint had threads at both ends for installation of anchorage plates (to ensure development of full tensile capacity when catenary action developed). The specimens were cast in two sequences. At first, half of each specimen was cast in plywood formwork with smooth surfaces. The second half was cast the day after. Before the second cast, grease was applied to the casting joint in order to reduce friction.

[Figure 2 about here.]

A regular concrete (denoted $\mathrm{C}$ in Table 1 ) with a maximum aggregate size of $16 \mathrm{~mm}$ and a commercial mortar (denoted $\mathrm{M}$ in Table 1) containing aggregate sizes of 0-2 mm were used to obtain three combinations of casting joints. The combinations were (see also Table 1): concrete-to-concrete (C/C), mortar-tomortar $(\mathrm{M} / \mathrm{M})$, and mortar-to-concrete $(\mathrm{M} / \mathrm{C})$. The main differences between the two materials are the aggregate composition and the compressive strength, see Table 2 for the proportions of the concrete mixture. All specimens were provided with rebars with diameter $d=8 \mathrm{~mm}$.

[Table 1 about here.]

[Table 2 about here.]

The specimens were tested in a classical push-off setup, where the thrust line of the applied load coincides with the plane of the casting joint in order to simulate pure shear loading, see Figure 3. The tests were performed in quasi-static deformation control with a constant rate of piston movement of 2.5 $\mathrm{mm} / \mathrm{min}$. Relative shear displacements in the joint were measured on both sides of the specimens using linear variable differential transducers.

[Figure 3 about here.]

\subsection{Test Results}

Figure 4 shows the measured load-displacement relationships for all tests. Within each test series (i.e. interface combinations $\mathrm{C} / \mathrm{C}, \mathrm{M} / \mathrm{M}$, and $\mathrm{M} / \mathrm{C}$ ) the 
load level for any given value of displacement, $u$, is roughly speaking proportional to the number of rebars crossing the joint. This indicates that the mutual distance $(42 \mathrm{~mm})$ between the rebars was sufficient to avoid group action. It was generally observed, that the specimens behaved almost linear elastic in the beginning. Then, gradually, the response curves became non-linear with loss of stiffness. By imposing further shear displacement, the load-displacement curves developed in a concave manner which led to increasing tangent stiffness. At a certain point, the tangent stiffness decreased again due to a convex development of the response curves. The convex development initiated partly as a result of the stress-strain relation of the reinforcement which at this point must have experienced hardening after initial yielding and hence the tangent stiffness decreases with increased shear displacement. This continues until the ultimate load, which was found at a maximum shear displacement in the range of 15-25 $\mathrm{mm}$. All tests were terminated by rupture of the rebars, and for the specimens with the same number of rebars, larger maximum shear displacement also resulted in higher ultimate loads. From post-test examinations of the specimens, severe local crushing of the concrete/mortar was observed near the interface as shown in Figure 5(a). Figure 5(b) shows a photo of the deflected shape of a ruptured rebar removed from a test specimen after testing. The plastic deformations of the rebar were concentrated within a length that corresponds to a few rebar diameters on both sides of the interface. Outside this region, the rebars remained straight, see Figure 5(b).

[Figure 4 about here.]

[Figure 5 about here.]

When comparing the response of specimens containing the same number of rebars, it is observed that specimens with $\mathrm{C} / \mathrm{C}$ interface carried the highest load at the point where the non-linear part of the response clearly emerges. This point is lowest for the curves belonging to specimens with M/M interface. As can be seen, this tendency is most pronounced for specimens with four rebars $(n=4)$ 
which seems reasonable since the largest difference between the compressive strengths of concrete and mortar was found for these tests, cf. Table 1. It should be noted, however, that although the response curves of the concrete specimens lie above those of the mortar specimens, then, at the final stage, specimens with mortar-to-mortar interface were actually able to carry the highest ultimate load. The results are interesting and indicate that while the compressive strength has a positive influence on the transition to non-linear behavior, then in the end, a higher compressive strength leads to lower ultimate load. The reason for this will be discussed in Section 4 .

On an overall level, the tested specimens behaved similar to tests reported by Engström [24] and Randl and Wicke [25]. However, Engström tested bolts with larger diameters which induced greater action in the concrete block and for this reason premature splitting failure of the concrete specimens was observed before rupture of the reinforcement/bolts occurred. Randl and Wicke reported similar load-displacement curves from tests on T-headed bars embedded in concrete. They observed shear displacements up to $20 \mathrm{~mm}$ and failure by rupture of the reinforcement. In their study, the interface properties were varied which influenced the shape of the load-displacement curves, especially at the transition to non-linear behavior.

\section{Second Order Plastic Modeling}

The non-linear part of the load-displacement response of two-sided dowel joints will in this paper be modeled by use of a simple second order plasticity approach where concrete as well as reinforcing steel are treated as rigid-plastic materials with finite deformation capacity. In the model, displacements are therefore the sole results of accumulated plastic deformations. The model will be established for the general case, where the casting joint is the interface between two different concretes (having different compressive strengths). Initially, the model is established for perfectly smooth joints. The effect of friction in the joint interface is then included by an extension of the model. 


\subsection{Mechanism and Kinematic Relationships}

The starting point of the model is to assume a failure mechanism for the rebar, see Figure 1, where two plastic hinges must develop to allow for relative displacement, $u$, in the joint. The position of the plastic hinges (defined by the distances $l_{1}$ and $l_{2}$ from the joint) depends on the strength of the concretes and the moment capacity of the rebar cross section. In order to comply with compatibility requirements, the plastic hinges must in addition to rotations also undergo elongations when $u$ increases. The rates of plastic deformations can be determined by establishing the kinematic relationship for the assumed mechanism. Then, by imposing the normality condition of plastic theory and by applying the work equation for increments of displacement, the necessary equations to determine the load $P$ as a function of displacement, $u$, can be derived.

The problem is treated as a static displacement controlled problem, where the relative shear displacement in the joint, $u$, is considered as a monotonic function of time. For convenience, a displacement velocity equal to unity is assumed:

$$
u(t)=t
$$

From simple geometrical considerations, the following relationship can be established between $u$ and the angle of rotation, $\theta$, in the plastic hinges:

$$
\tan \theta=\frac{u}{l_{1}+l_{2}}=\frac{u_{1}}{l_{1}}=\frac{u_{2}}{l_{2}}
$$

where $u_{1}+u_{2}=u$, see Figure 1 . To accommodate the change of geometry when $u$ increases, it is necessary to impose elongation in the rebar in addition to rotation of the plastic hinges. Since rigid-plastic material behavior has been assumed, it is convenient to consider the elongation as a plastic extension, $\Delta$, concentrated in the hinges (as indicated in Figure 1). In this way, $\theta$ and $\Delta$ may be regarded as the general strains in the plastic hinges, which are subjected to general stresses in the form of bending moments, $M$, and normal forces, $N$. The 
following relationship between $u$ and $\Delta$ can be established:

$$
\Delta=-\frac{l_{1}+l_{2}}{2}+\frac{l_{1}+l_{2}}{2} \sqrt{1+\left(\frac{u}{l_{1}+l_{2}}\right)^{2}}
$$

Based on Equations (1)-(3), the rates of plastic deformations in the hinges can be determined as follows:

$$
\begin{aligned}
& \dot{\theta}=\frac{d \theta}{d t}=\frac{d \theta}{d u} \frac{d u}{d t}=\frac{l_{1}+l_{2}}{\left(l_{1}+l_{2}\right)^{2}+u^{2}} \\
& \dot{\Delta}=\frac{d \Delta}{d t}=\frac{d \Delta}{d u} \frac{d u}{d t}=\frac{u}{2 \sqrt{\left(l_{1}+l_{2}\right)^{2}+u^{2}}}
\end{aligned}
$$

Finally, by use of Equations (4) and (5), the following condensed expression for the kinematical condition of the rebar can be established:

$$
\frac{\dot{\Delta}}{\dot{\theta}}=\frac{u}{2} \sqrt{1+\left(\frac{u}{l_{1}+l_{2}}\right)^{2}}
$$

\subsection{Constitutive Relationship and Sectional Forces in the Plastic Hinges}

The assumption of rigid-plastic material behavior implies that in the case of pure tension, plastic deformation in the rebar is only possible when the cross section is subjected to the plastic tensile capacity $N_{p}$. Further, in the case of pure bending, plastic deformation is only possible when the cross section is subjected to the plastic moment capacity $M_{p}$. These sectional capacities are:

$$
\begin{aligned}
N_{p} & =\frac{\pi}{4} d^{2} f_{y} \\
M_{p} & =\frac{1}{6} d^{3} f_{y}
\end{aligned}
$$

where $d$ is the cross sectional diameter of the rebar and $f_{y}$ is the yield stress of the rebar. For combinations of bending and axial tension, plastic deformations may initiate when the yield condition of the cross section is fulfilled, i.e. when $f(M, N)=0$. The yield condition (or the MN-interaction diagram) can be derived by requiring static equivalence between the sectional forces $(M, N)$ and the distribution of normal stresses shown in Figure 6. The result appears as 
follows:

$$
f(N, M)=\frac{N}{N_{p}}+\frac{2}{\pi}\left(\arcsin \left(\left(\frac{M}{M_{p}}\right)^{\frac{1}{3}}\right)-\left(\frac{M}{M_{p}}\right)^{\frac{1}{3}} \sqrt{1-\left(\frac{M}{M_{p}}\right)^{\frac{2}{3}}}\right)-1=0
$$

[Figure 6 about here.]

As an approximation, the mathematically simpler yield condition for a rectangular cross section is sometimes adopted when studying dowel and catenary action in rebars, see e.g. [21-23, 25].

Now, according to the normality condition of plastic theory, the rates of plastic deformations must fulfill the following constitutive relationship:

$$
\begin{aligned}
& \dot{\theta}=\lambda \frac{\partial f}{\partial M}=\lambda \frac{8}{\pi d^{3} f_{y}} \frac{1}{\sqrt{1-\left(\frac{M}{M_{p}}\right)^{2 / 3}}} \\
& \dot{\Delta}=\lambda \frac{\partial f}{\partial N}=\lambda \frac{4}{\pi d^{2} f_{y}}
\end{aligned}
$$

where $\lambda$ is a positive constant proportional to the displacement velocity. The constant vanishes when Equations (10) and (11) are used to establish the following ratio of plastic strain rates:

$$
\frac{\dot{\Delta}}{\dot{\theta}}=\frac{d}{2} \sqrt{1-\left(\frac{M}{M_{p}}\right)^{2 / 3}}
$$

It can be seen that Equation (12) together with Equation (6) provides a link between the kinematical conditions and the state of stresses in the plastic hinges. This means that the bending moment, $M(u)$, carried by the plastic hinges for any given value of displacement, $u$, can be determined by equating the right hand side of Equation (6) to the right hand side of Equation (12). The tension force, $N(u)$, may thereafter be determined by imposing $f(M, N)=0$ 
according to Equation (9). The results are:

$$
\begin{aligned}
& \frac{M(u)}{M_{p}}=\left(1-\left(\frac{u}{d}\right)^{2}\left(1+\left(\frac{u}{l_{1}+l_{2}}\right)^{2}\right)\right)^{3 / 2} \nless 0 \\
& \frac{N(u)}{N_{p}}=1-\frac{2}{\pi}\left(\arcsin \left(\left(\frac{M(u)}{M_{p}}\right)^{\frac{1}{3}}\right)-\left(\frac{M(u)}{M_{p}}\right)^{\frac{1}{3}} \sqrt{1-\left(\frac{M(u)}{M_{p}}\right)^{\frac{2}{3}}}\right) \ngtr 1
\end{aligned}
$$

The ratio $M(u) / M_{p}$ in Equation (14) may be replaced by the right hand side of Equation (13) in order to obtain an explicit expression for the normal force in the rebar as a function of $u$.

\subsection{Effective Stress Distribution in the Concrete}

The assumed displacement field for the rebar implies that it has to cut its way through the concrete and thereby cause local crushing failure. It is in this context not possible on the basis of the present simplified approach to determine in details the entire stress distribution in the concrete. For triaxial stress conditions of the type developed in the concrete at the dowel, an enhanced compressive strength, $f_{c c}$, is therefore usually assumed:

$$
f_{c c}=c f_{c}
$$

where $c \geq 1$ is the so-called enhancement factor which has to be determined by calibration with test results. Rasmussen [13] found $c$-values in the range of 3.75.4 from tests on one-sided dowels. Similar $c$-values have also been suggested in Refs. [1, 23, 27]. There is a close link between the average triaxial compressive strength, $f_{c c}$, and the position of the plastic hinges. Rasmussen [13] used a simple plasticity approach to establish this link, which eventually led to an estimate of the load carrying capacity related to pure dowel action (i.e. the so-called first order plastic solution). The same approach is adopted in the 
following for two-sided dowels in order to determine the distances $l_{1}$ and $l_{2}$. As shown in Figure 7(a), it is assumed that contact pressures of magnitude $f_{c c, 1}$ and $f_{c c, 2}$ are acting uniformly on the rebar over the lengths $l_{1}$ and $l_{2}$, respectively, when the rebar starts to carry load by pure dowel action (see also Nielsen and Hoang [28]). The corresponding shear and moment diagrams for the rebar are shown in Figure 7(a) as well. By setting up the vertical force equilibrium and moment equilibrium for the part of the rebar between the two plastic hinges, it is possible to establish the following equations to calculate $l_{1}$ and $l_{2}$ :

[Figure 7 about here.]

$$
\begin{aligned}
& l_{1}=\sqrt{\frac{2}{3}} \frac{d}{\sqrt{1+\frac{f_{c c, 1}}{f_{c c, 2}}}} \sqrt{\frac{f_{y}}{f_{c c, 1}}} \\
& l_{2}=\sqrt{\frac{2}{3}} \frac{d}{\sqrt{1+\frac{f_{c c, 2}}{f_{c c, 1}}}} \sqrt{\frac{f_{y}}{f_{c c, 2}}}
\end{aligned}
$$

When setting up the equilibrium equations leading to Equations (16) and (17), it has been utilized that the moment capacity, $M_{p}$, of the rebar cross section is given by Equation (8). In the case of identical material properties on both sides of the joint, i.e. $f_{c c, 1}=f_{c c, 2}$, Equations (16) and (17) will, as expected, be identical to the results presented in Nielsen and Hoang [28]. It should be noted that the assumed uniform distribution of contact pressures only leads to zero moment in the rebar at the interface when $f_{c c, 1}=f_{c c, 2}$ (see moment diagram in Figure $7(\mathrm{a})$ ). Hence, to maintain equilibrium when $f_{c c, 1} \neq f_{c c, 2}$ and when the external action corresponds to pure shear (i.e. thrust line coinciding with interface plane), tension must develop in the rebar which eventually leads to a distribution of so-called clamping stresses in the interface. The tension force together with the clamping stresses will then be able to outbalance the (small) bending moment in the rebar at the interface cross section. According to Equation (14), tension develops in the rebar as soon as $u>0$. Therefore, 
strictly speaking, the assumption of uniformly distributed contact pressure is not able to fulfill all equilibrium requirements at $u=0$ (i.e. initiation of pure dowel action) when $f_{c c, 1} \neq f_{c c, 2}$. This is, however, acceptable since the assumption primarily was motivated by the aim of obtaining a simple estimate of the position of the plastic hinges. In reality, the rebar will probably experience combinations of tension and bending moments already in the elastic range.

The simple stress distribution shown in Figure 7(a) cannot be adopted for analysis of the entire load-displacement response. When dowel action is accompanied by tension in the rebar (and in the end completely replaced by catenary action) the average contact pressure must decrease due to the assumed material properties and the equilibrium conditions. Since concrete is not a perfectly rigid-plastic material, there will be a softening effect which in turn reduces the concrete pressure when the concrete experiences too large compressive strains. The displacement, $u$, and thereby the local deformations may become so large that the concrete near the joint interface spalls off/crushes thus leaving this zone to be stress free, see e.g. Figure 5(a). Therefore, due to material properties, redistribution of the contact pressure will take place as $u$ increases. In addition to this, the redistribution of stresses must take place in such a way, that equilibrium can be maintained when catenary action starts to develop in the rebar.

It is not possible in a rigid-plastic model to theoretically account for the above mentioned softening of the concrete. Therefore, in the following, as $u$ increases, the effect of softening (and spalling of concrete) will indirectly be taken into account by introducing effective lengths, $l_{1, \text { ef }}$ and $l_{2, \text { ef }}$, over which contact pressures $f_{c c, 1}$ and $f_{c c, 2}$ are assumed to act uniformly, see Figure 7(b). This may be interpreted as an assumption of rigid-plastic behavior with finite deformation capacity, although there is actually no real information about the deformation capacity of the concrete when it is subjected to contact pressure by the dowel. The only simple way to establish the condition for $l_{1 \text {,ef }}$ and $l_{2, \mathrm{ef}}$, as $u$ increases, is therefore through equilibrium considerations. Hence, by establishing vertical force equilibrium and moment equilibrium for the part of the rebar between the 
plastic hinges, see Figure 7(b), and by utilizing that the plastic hinges now are subjected to $M(u)$ and $N(u)$ as given by Equations (13) and (14), the following relationship between $u$ and the effective lengths $l_{1 \text {,ef }}$ and $l_{2, \text { ef }}$ can be established:

$$
l_{i, \mathrm{ef}}=l_{i}\left(1-\sqrt{1-\frac{M(u)}{M_{p}+\left(\frac{u}{2}\right)^{2} d \frac{f_{c c, 1} f_{c c, 2}}{f_{c c, 1}+f_{c c, 2}}}}\right) \nless 0
$$

where $i=1$ and 2 . It appears that the effective length is equal to the initial lengths, cf. Equations (16) and (17), when $u=0$ and reduces to zero when $u$ has reached a value that makes $M(u)=0$. The latter situation corresponds to a transition to full catenary action where the plastic hinges turn into moment-free hinges. Therefore, the rebar will no longer experience contact pressure between the two hinges, but instead acts as a tie.

\subsection{Deformation Capacity of Rebars}

As described in the previous, all push-off tests were terminated when rupture of the rebars took place, i.e. when the deformation capacity of the rebar was reached. To capture this effect in the model, it is necessary to express the deformation capacity of the rebar in terms of the plastic elongation in the hinges. This means that an upper limit, $\Delta_{\max }$, must be introduced such that Equation (3) may be used to determine the displacement capacity, $u_{\max }$, of the system. An estimate of $\Delta_{\max }$ can be obtained from a detailed study of the tension tests of the reinforcement. Figure 8(a) shows four tested stress-elongation relationships for the type of rebar used in this study. The measured elongations represent the strain accumulations over the so-called necking zone. The results were obtained by using digital image correlation (DIC) analysis based on images taken at approximately 0.25 hertz with a 36 megapixel camera. An example of results of a DIC analysis, showing strain localization in the rebar just before rupture, can be seen in Figure 8(b). The curves in Figure 8(a) were determined by postprocessing of the digital strain measurements, where it was possible to isolate the elongation over a distance of two times the rebar diameter, $2 d$, within which 
strain localization took place. Based on the results in Figure 8(a), an elongation capacity of $\Delta_{\max }=3 \mathrm{~mm}$ is adopted. It should in this context be noted that the standard methods for determination of nominal strain capacity of reinforcing steel cannot be used to estimate $\Delta_{\max }$. This is so because the nominal strain capacity is based on a reference length, which is much longer than the necking zone as well as the characteristic length of the present problem, i.e. the distance between the two plastic hinges.

[Figure 8 about here.]

\subsection{Load-displacement Response of Frictionless Joints}

Based on the obtained results and the assumptions made, it is now possible to determine the load-displacement response by use of the work equation. For this purpose, a stationary situation with displacement $u$ and load $P(u)$ is used as the starting point from which an increment of displacement, $\delta u$, is considered. The external work, $W_{E}$, is then given by:

$$
W_{E}=P(u) \delta u
$$

The internal work, $W_{I}$, has contributions from the energy dissipated in the plastic hinges as well as the energy absorbed when the concrete crushes at the rebar. The following formula can be derived:

$W_{I}=f_{c c, 1} l_{1, \mathrm{ef}} d\left(\frac{1}{2} \frac{l_{1, \mathrm{ef}}}{l_{1}} \delta u_{1}\right)+f_{c c, 2} l_{2, \mathrm{ef}} d\left(\frac{1}{2} \frac{l_{2, \mathrm{ef}}}{l_{2}} \delta u_{2}\right)+2 N(u) \delta \Delta+2 M(u) \delta \theta$

where the incremental displacement and deformation quantities, $\delta u_{1}, \delta u_{2}$, $\delta \Delta$, and $\delta \theta$, can be expressed in terms of $\delta u$ through the following relationships (with $\delta t=\delta u$ according to Equation (1)):

$$
\begin{aligned}
\delta \theta & =\dot{\theta} \delta u \\
\delta \Delta & =\dot{\Delta} \delta u \\
\delta u_{1} & =\frac{l_{1}}{l_{1}+l_{2}} \delta u \\
\delta u_{2} & =\frac{l_{2}}{l_{1}+l_{2}} \delta u
\end{aligned}
$$


Now, by inserting the right hand side of Equations (21)-(24) into Equation (20) and by setting up the work equation, i.e. $W_{E}=W_{I}$, the following solution is obtained for the load-displacement response of a perfectly smooth two-sided dowel joint:

$$
P_{\mathrm{S}}(u)= \begin{cases}\frac{1}{2} f_{c c, 1} d \frac{l_{1, \text { ef }}^{2}}{l_{1}+l_{2}}+\frac{1}{2} f_{c c, 2} d \frac{l_{2, \text { ef }}^{2}}{l_{1}+l_{2}}+2 N(u) \dot{\Delta}+2 M(u) \dot{\theta}, & \text { for } \quad N(u)<N_{p} \\ 2 N_{p} \dot{\Delta}, & \text { for } \quad N(u)=N_{p}\end{cases}
$$

Here $M(u), N(u), \dot{\Delta}, \dot{\theta}, l_{1, \text { ef }}$, and $l_{2, \text { ef }}$ can be expressed as explicit functions of the displacement $u$ as shown earlier. The solution is valid as long as $u$ is less than the displacement capacity, $u_{\max }$, which can be calculated from Equation (3) by inserting the deformation capacity of the rebar, $\Delta_{\max }$. The index $s$ in $P_{s}(u)$ indicates that this solution applies to a smooth interface without friction. How to include effects of friction will be shown in the next section.

Solution (25a) applies to the regime, where a combination of dowel action and catenary action exists in the rebar while pure catenary action (i.e. $M=0$ in the plastic hinge) is described by Equation (25b).

Figure 9 shows an example of a response curve, $P_{\mathrm{s}}(u)$, as predicted by Equation (25). The calculations were performed by use of the parameters given in Table 3. In the figure the different contributions to the response are indicated with dashed colored lines and the total is represented by a solid line. The transition from combined dowel and catenary action to pure catenary action is indicated with a cross. It appears that the load-displacement response follows a descending branch (local drop) when the regime with in-elastic deformations initiates. The local drop is a result of the material assumptions adopted in the model which at the onset of in-elastic deformation estimates the capacity assuming a uniform distribution of contact stresses at the dowel, see Figure 7(a). When the in-elastic shear displacement is increased, the equilibrium considerations applied in the deformed state, see Figure 7(b), cause the load to drop locally. 
As the contribution from the normal force, $N(u)$, increases with increasing displacement, the load starts to increase monotonically until a point where the deformation capacity of the rebar is exhausted and the load drops to zero.

[Figure 9 about here.]

[Table 3 about here.]

\subsection{Inclusion of Friction}

The model presented in the previous applies to perfectly smooth joints. However, casting joints can seldom be characterized as totally frictionless and it is therefore important for practical applications to take into account the contribution from interface friction. It turns out that the model actually provides most of the information needed to include the effect of friction on the loaddisplacement response. Figure 10 illustrates a free body diagram of half of the specimen. It is assumed that the interface has a roughness that corresponds to a friction coefficient of $\mu$. At any given displacement, $u$, the tension force in the rebar, $N(u)$, can be determined by Equation (14). The tension force causes compressive normal stresses to develop in the interface. The resultant of these so-called clamping stresses is equal to the horizontal projection of $N(u)$. Then, from simple shear-friction considerations, the following would be the contribution from friction to the load carrying capacity:

$$
P_{\mathrm{f}}(u)=\mu N(u) \cos \theta
$$

[Figure 10 about here.]

Here index $f$ indicates that the contribution relates to friction and the angle $\theta$ is given by Equation (2). The total load-displacement response when including the effect of dowel and catenary action as well as the effect of friction then amounts to:

$$
P_{\text {total }}(u)=P_{\mathrm{s}}(u)+P_{\mathrm{f}}(u)
$$

Recently Santos and Júlio [29] gave an overview of the suggested values for the coefficient of friction related to shear-friction theory. The values vary widely 
and some of the earlier contributors to this area, e.g. Birkeland and Birkeland [30], suggested values for artificially roughened surfaces (in the order of $\mu=1.4$ ) and $\mu=0.8-1.0$ for construction joints. However, it should be noted that these rather high values were suggested/calibrated for a model, where all resistance in the joint was assumed to be due to friction without consideration of dowel action. Bennett [31] suggested a combination of friction (with $\mu=0.6$ ) and dowel action including a moment in the interface, however, without combination of bending and tension in the rebar. Engström [24] introduced a model which combines friction and dowel action, taking combinations of bending and tension in the rebar into account, and he suggested that $\mu=0.3-0.6$ should be used for concrete-to-concrete interface friction. Randl and Wicke [25] also considered combinations of dowel action and tension with friction and suggested $\mu=0.5$ for smooth interfaces. These previous works did, however, not contain a solution for how to relate the shear displacement, $u$, in the joint with the sectional forces carried by the rebar. The suggested coefficients of friction (based on model calibration) are therefore partly influenced by the estimate of the clamping forces. In the experimental program of this study, the smooth interfaces were, as mentioned, treated with grease before casting of the second batch to minimize friction. The friction coefficient should therefore be less than that suggested by Randl and Wicke and most probably in the lower end of the range suggested by Engström. In the following a coefficient of friction in the order of $\mu=0.3$ is adopted. This value of $\mu$ has been used to determine the load-displacement relationships shown in Figure 11, calculated by Equation (27). The capacity without friction, i.e. $P_{s}(u)$, as well as the development of the frictional contribution, $P_{f}(u)$, are also shown as dashed lines. It can be seen that after the point of transition to pure catenary action (i.e. $N(u)=N_{p}$ ), the contribution from friction decreases. The reason for this is of course that the clamping force decreases as the angle of rotation, $\theta$, increases. It appears from Figure 11 that friction does not have an influence on the first order plastic solution for pure dowel action. The response curve, however, is shifted upwards once the rebar starts to carry tensile forces and friction is activated. 
[Figure 11 about here.]

\section{Comparison of Model with Test Results}

The load-displacement response predicted by the model, Equation (27), has been compared with the experimental results and depicted in Figures 12-14. The basic input parameters have been obtained from Table 1. By adopting a friction coefficient of $\mu=0.3$ as argued for in the previous, there is only the enhancement factor, $c$, left to calibrate the model with test results.

For concrete, a value of $c=5$ is adopted, similar to the findings of Vintzēleou and Tassios [3]. To obtain reasonable agreement with tests, a smaller value has been adopted for mortar, namely $c=4$. The fact that the enhancement factor should be smaller in the case of mortar may possible be explained by the relatively more brittle behavior of mortar (as compared to concrete) due to the relatively less aggregate content as well as the relatively smaller average aggregate size.

As can be seen in Figure 12-14, the model predictions consist of an upper and a lower curve with the area in between shaded in grey. The lower curves represent calculations based on the yield stress, $f_{y}$, while the upper curves are based on calculations where $f_{y}$ in the model has been replaced by the tensile strength $f_{u}$. Calculations with $f_{u}$ have been included because hardening of reinforcement is not included in the model. The shaded area between the two limiting curves thus indicates the expected range of test results.

The model only predicts the non-linear behavior. The calculated response curves have therefore been shifted horizontally to a displacement, $u_{0}$, where the plastic behavior begins. This is shown in the figures with a shaded light grey area and is in Figure 12(a) indicated by arrows showing 'elastic regime' and 'plastic regime'. To determine the horizontal shift, an estimate of the maximum displacement in the elastic regime has to be derived. In the present work, this estimate has been obtained by modeling the rebar as a beam on an elastic foundation with a constant stiffness, e.g. as shown in Refs. [2-10]. The calculations can be seen in 
Appendix A. Despite the simplicity of the elastic model, Equation (A.1) actually provides a reasonable estimate of the displacement, $u_{0}$, where the in-elastic displacement regime begins.

It can be seen that with the adopted enhancement factors, $c$, and the coefficient of friction, $\mu$, the general development of the tested response curves is captured rather well. The predicted response also displays a concave development followed by a convex development, although not entirely coinciding with the tested response. As mentioned earlier, the test responses show a dependency of the compressive strength of the concrete. The model explains some of these observations. As already shown by Rasmussen [13], the load that causes transition to the non-linear behavior is proportional to the geometric mean of $f_{c}$ and $f_{y}$, which is observed e.g. in Figure 4. On the other hand, the ultimate load at a high shear displacement is a result of catenary action, where change of geometry plays an important role. Here, a lower compressive strength of the concrete (or mortar) is beneficial for catenary action because this requires plastic deformation over a longer length of the rebar and at the same time makes it easier for the rebar to cut its way through the concrete (or mortar). This eventually leads to larger maximum displacement and thereby also a higher ultimate load. This is, to some extend, captured by the model. In addition, the calculations based on $f_{u}$ provide the best estimate of the ultimate peak load. This result is as expected since the peak load corresponds to reinforcement rupture (as observed in tests).

As a final remark, it should be noted that although the model does not agree with test results in all aspects, then for robustness assessment, the model seems to have potential for practical use. The reason for this is that in a robustness analysis, the dissipated plastic energy (i.e. the area below the response curve) is a main concern. In this respect, and based on Figures 12-14, the model seems to be able to provide a reasonable estimate of the available plastic energy.

[Figure 12 about here.]

[Figure 13 about here.] 
[Figure 14 about here.]

\section{Conclusions}

Push-off tests of two-sided dowel joints have been performed and a simple, second order plasticity model has been developed to predict the in-elastic regime of the load-displacement response. The main experimental observations were:

- The load-displacement relationships were non-linear and consisted of convex followed by concavely shaped curves. The load increased with increasing shear displacement until the ultimate capacity corresponding to rupture of the rebar(s) was reached

- A mutual distance of $5.25 d$ between the rebars in the interface plane did not lead to any observable group effect, as the magnitude of the results from specimens with $n>1$ were proportional to the results of specimens with a single rebar $(n=1)$

- Higher compressive strength of the concrete/mortar led to a higher load at the transition point between linear and non-linear behavior

- Specimens with a relatively lower compressive strength had a greater displacement capacity and a higher ultimate load than specimens with a relatively higher compressive strength

Despite the simplicity and the relatively small number of required input parameters, the developed second order plasticity model captured the main characteristics of the tested load-displacement responses well. Calculations based on the yield stress of the reinforcement provided an appropriate estimate of the load level, where non-linear behavior initiates. A reasonable estimate of the ultimate capacity at large shear displacements could be calculated by use of the ultimate strength of the reinforcement. The model has potential for practical assessment of structural robustness, where estimation of available plastic energy (area below load-displacement response) is important. 


\section{Acknowledgment}

The experimental research presented in this paper was financially supported by the COWI Foundation. The experimental work was supported by M.Sc. Nikolai Bach and M.Sc. Martin Hansen during their master thesis. The authors gratefully acknowledge these valuable contributions.

\section{References}

[1] fib, Bulletin 43: Structural Connections for Precast Concrete Buildings, Fédération international du béton, Lausanne, Switzerland, 2008.

[2] B. F. Friberg, Design of Dowels in Transverse Joints of Concrete Pavements, American Society of Civil Engineers 64 (9) (1938) 1809-1828.

[3] E. N. Vintzeleou, T. P. Tassios, Mathematical Models for Dowel Action under Monotonic and Cyclic Conditions, Magazine of Concrete Research 38 (134) (1986) 13-22.

[4] S. Dei Poli, M. Di Prisco, P. G. Gambarova, Shear Response, Deformations, and Subgrade Stiffness of a Dowel Bar Embedded in Concrete, ACI Structural Journal 89 (6) (1992) 665-675.

[5] S. Dei Poli, M. di Prisco, P. G. Gambarova, Cover and Stirrup Effects on the Shear Response of Dowel Bar Embedded in Concrete, ACI Structural Journal 90 (4) (1993) 441-450.

[6] S. S. Mannava, T. D. Bush Jr., A. R. Kukreti, Load-Deflection Behavior of Smooth Dowels, ACI Structural Journal 96 (6) (1999) 891-898.

[7] N. Randl, Load Bearing Behaviour of Cast-in Shear Dowels, Beton- und Stahlbetonbau 102 (S1) (2007) 31-37.

[8] Y. Tanaka, J. Murakoshi, Reexamination of Dowel Behavior of Steel Bars Embedded in Concrete, ACI Structural Journal 108 (6) (2011) 659-668. 
[9] X. G. He, A. K. H. Kwan, Modeling Dowel Action of Reinforcement Bars for Finite Element Analysis of Concrete Structures, Computers and Structures 79 (6) (2001) 595-604.

[10] B. El-Ariss, Behavior of Beams With Dowel Action, Engineering Structures 29 (6) (2007) 899-903.

[11] H. Marcus, Load Carrying Capacity of Dowels at Transverse Pavement Joints, Journal of the American Concrete Institute 23 (2) (1951) 169-194.

[12] P. Soroushian, K. Obaseki, M. C. Rojas, Bearing Strength and Stiffness of Concrete under Reinforcing Bars, ACI Materials Journal 84 (3) (1987) 179-184.

[13] B. Højlund Rasmussen, Betonindstøbte tværbelastede boltes og dornes bæreevne, English: Resistance of Embedded Bolts and Dowels Loaded in Shear, Bygningsstatiske meddelelser 34 (2) (1963) 39-55.

[14] C. R. Calladine, Simple Ideas in the Large-Deflection Plastic Theory of Plates and Slabs, in: J. Heyman, F. A. Leckie (Eds.), International Conference on the Applications of Plastic Theory in Engineering Design, Cambridge, UK, 1968, pp. 93-127.

[15] M. W. Bræstrup, Dome Effect in RC Slabs: Rigid-Plastic Analysis, Journal of the Structural Division - ASCE 106 (6) (1980) 1237-1253.

[16] L. M. Belenkiy, Upper-Bound Solutions for Rigid-Plastic Beams and Plates of Large Deflections by Variation Principles, Journal of Engineering Mechanics 133 (1) (2007) 98-105.

[17] C. G. Bailey, W. S. Toh, B. M. Chan, Simplified and Advanced Analysis of Membrane Action of Concrete Slabs, ACI Structural Journal 105 (1) (2008) 30-40.

[18] Y. Mirzaei, Post-Punching Behavior of Reinforced Concrete Slabs, Ph.D. thesis, École Polytechnique Fédérale de Lausanne (2010). 
[19] M. Fernández Ruiz, Y. Mirzaei, A. Muttoni, Post-Punching Behavior of Flat Slabs, ACI Structural Journal 110 (5) (2013) 801-812.

[20] D. Gouverneur, R. Caspeele, L. Taerwe, Experimental Investigation of the Load-Displacement Behaviour under Catenary Action in a Restrained Reinforced Concrete Slab Strip, Engineering Structures 49 (2013) 1007-1016.

[21] H. Dulácska, Dowel Action of Reinforcement Crossing Cracks in Concrete, ACI Journal 69 (12) (1972) 754-757.

[22] S. G. Millard, R. P. Johnson, Shear Transfer Across Cracks in Reinforced Concrete due to Aggregate Interlock and to Dowel Action, Magazine of Concrete Research 36 (126) (1984) 9-21.

[23] E. N. Vintzeleou, T. P. Tassios, Behavior of Dowels under Cyclic Deformations, ACI Structural Journal 84 (1) (1987) 18-30.

[24] B. Engström, Combined Effects of Dowel Action and Friction in Bolted Connections, Nordic Concrete Research 9 (1990) 14-33.

[25] N. Randl, M. Wicke, Schubübertragung zwischen Alt- und Neubeton, Beton- und Stahlbetonbau 95 (Heft 8) (2000) 461-473.

[26] J. H. Sørensen, L. C. Hoang, J. F. Olesen, G. Fischer, Catenary Action in Rebars Crossing a Casting Joint Loaded in Shear, in: Proceedings of the 11th fib International PhD Symposium in Civil Engineering, 2016, pp. $735-742$.

[27] fib, fib Model Code for Concrete Structures 2010, Wilhelm Ernst \& Sohn, Lausanne, Switzerland, 2013.

[28] M. P. Nielsen, L. C. Hoang, Limit Analysis and Concrete Plasticity, 3rd Edition, CRC Press, Taylor \& Francis Group, Boce Raton, 2011.

[29] P. M. D. Santos, E. N. B. S. Júlio, A State-of-the-art Review on ShearFriction, Engineering Structures 45 (2012) 435-448. 
[30] P. W. Birkeland, H. W. Birkeland, Connections in Precast Concrete Construction, ACI Journal 63 (3) (1966) 345-368.

[31] E. W. Bennett, S. Banerjee, Strength of Beam-Column Connections with Dowel Reinforcement, The Structural Engineer 54 (4) (1976) 133-139. 


\section{List of Figures}

$1 \quad$ Casting joint between two different concretes subjected to shear displacements and crossed by a r 2 General geometry of test specimens for push-off shear tests and indication of position of rebars in 3 Test setup for push-off testing of casting joints crossed by rebar(s) 29

4 Test results from all specimens . . . . . . . . . . . . 30

$5 \quad$ Local crushing at rebars at the casting joint (a) and deflected shape of ruptured rebar (b) 31

$6 \quad$ Plastic stress distribution in a circular cross section subjected to $M$ and $N 32$

$7 \quad$ Position of plastic hinges and extent of distribution of contact pressure at initiation of pure dowe 8 Local stress-elongation relationship for rebars and indication of the measurement length spanning

$9 \quad$ Load-displacement response of a single rebar crossing a frictionless joint 35

10 Contribution of friction in the interface . . . . . . . . . . . . . . 36

11 Inclusion of interface friction to the model response . . . . . . . 37

12 Comparison of model with test results - 1 rebar . . . . . . . . . 38

13 Comparison of model with test results - 2 rebars . . . . . . . . . . 39

14 Comparison of model with test results - 4 rebars . . . . . . . . . . 40 


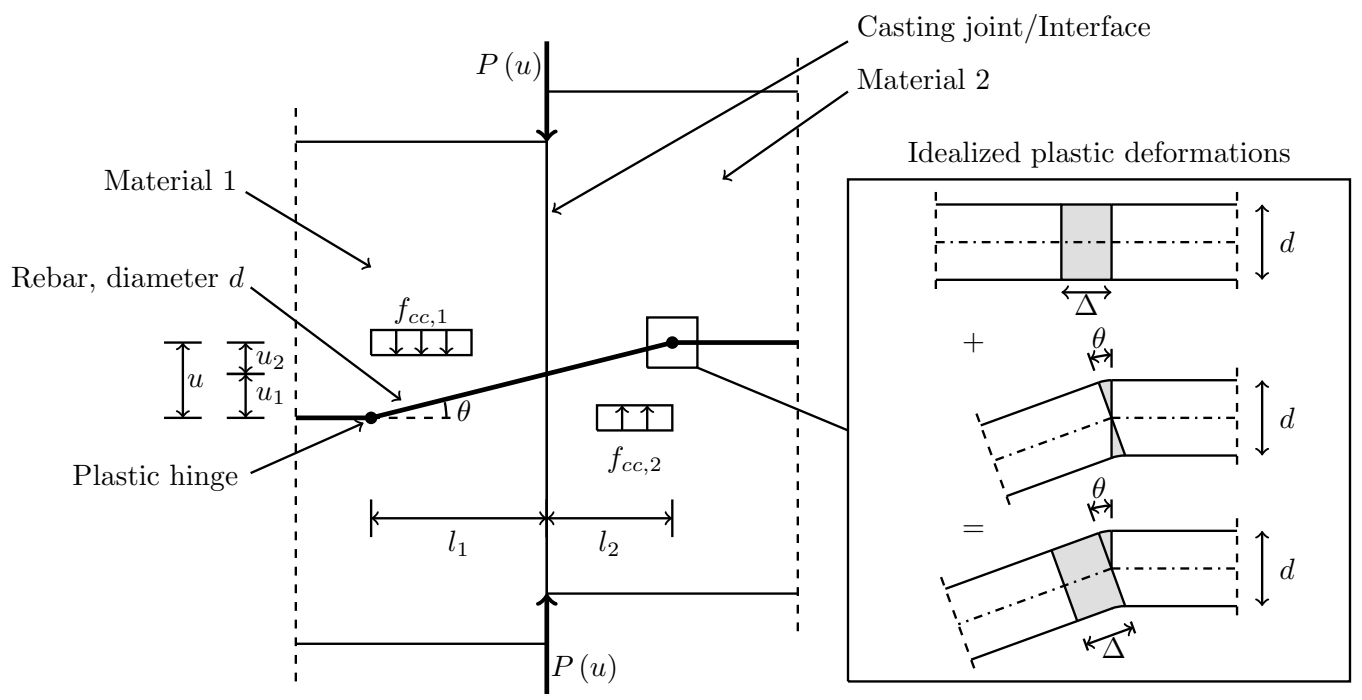

Figure 1: Casting joint between two different concretes subjected to shear displacements and crossed by a rebar 


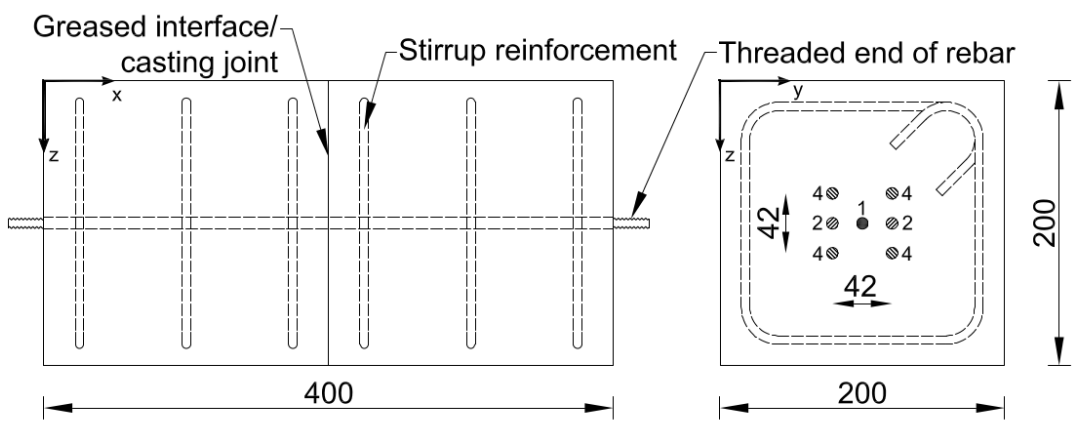

Figure 2: General geometry of test specimens for push-off shear tests and indication of position of rebars in specimens with $n=1,2$ and 4 rebars 


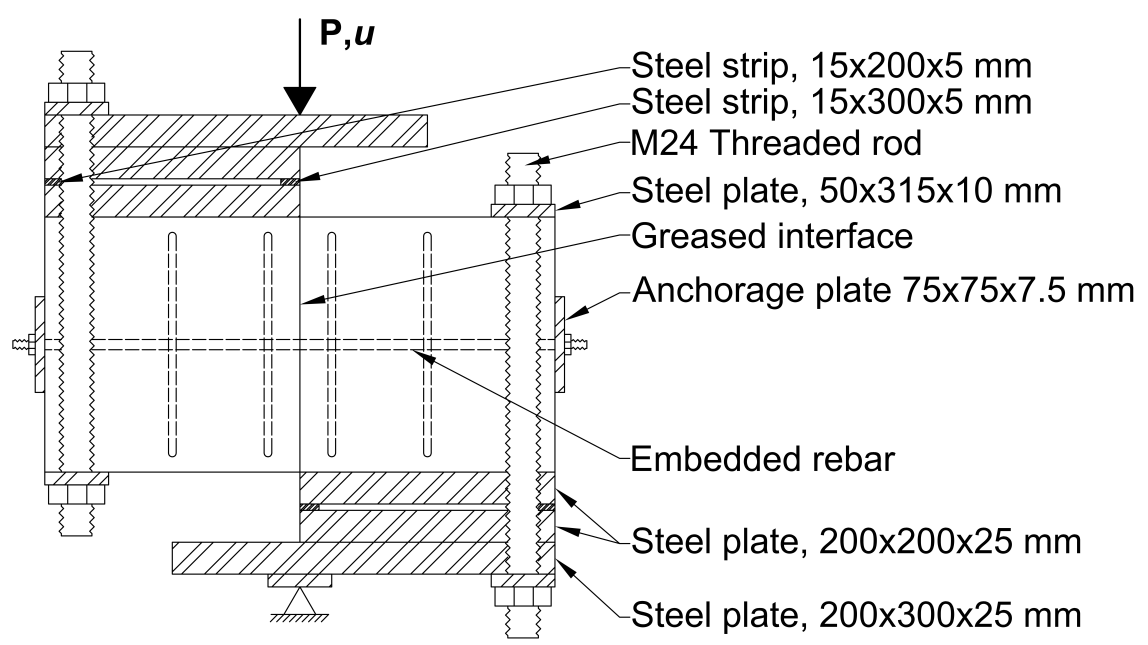

Figure 3: Test setup for push-off testing of casting joints crossed by rebar(s) 


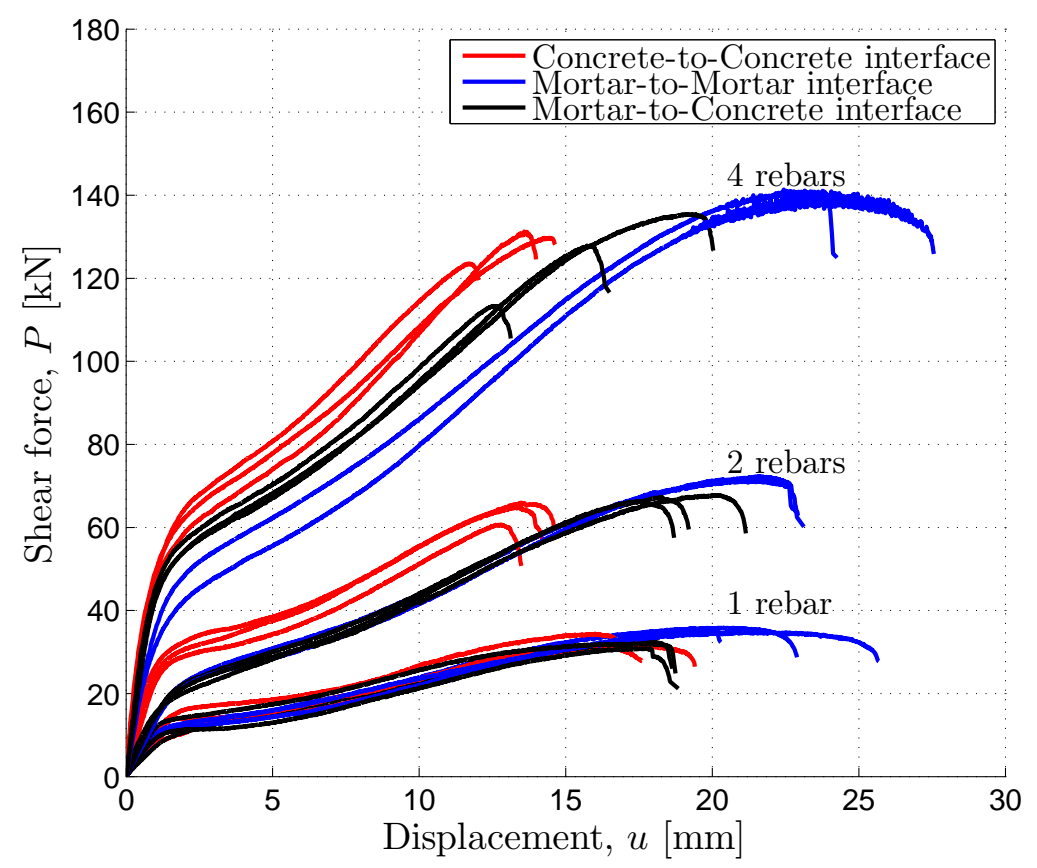

Figure 4: Test results from all specimens 


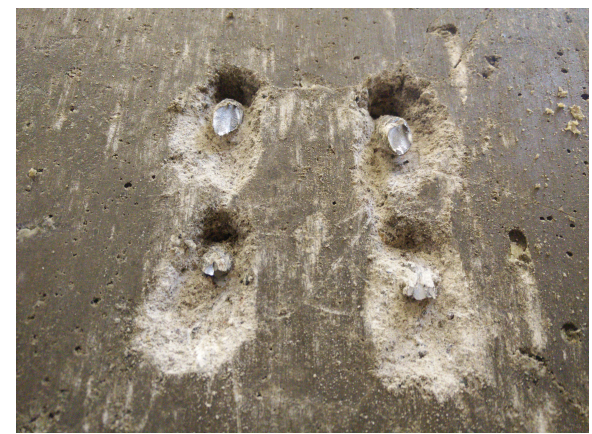

(a) Local crushing of mortar/concrete

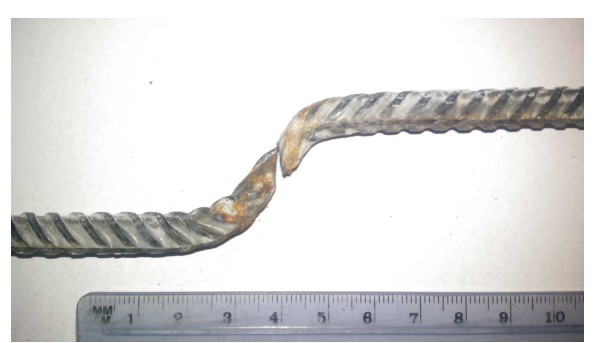

(b) Rupture of rebar

Figure 5: Local crushing at rebars at the casting joint (a) and deflected shape of ruptured rebar (b) 


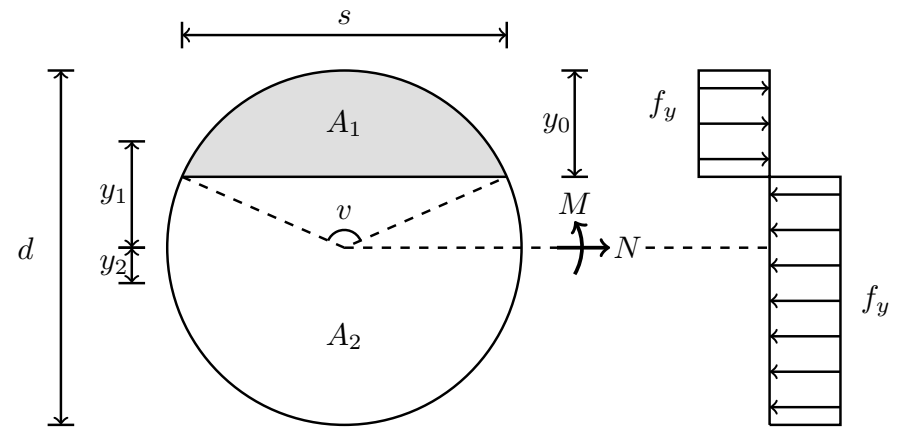

Figure 6: Plastic stress distribution in a circular cross section subjected to $M$ and $N$ 


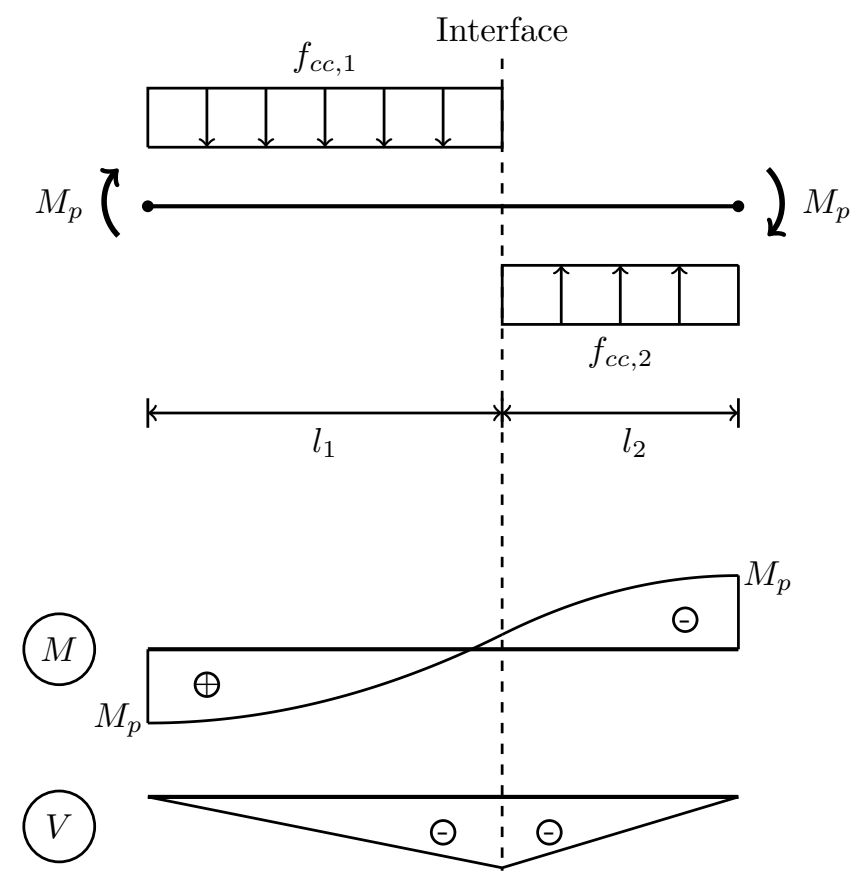

(a) Undeformed state and distribution of moment and shear in rebar

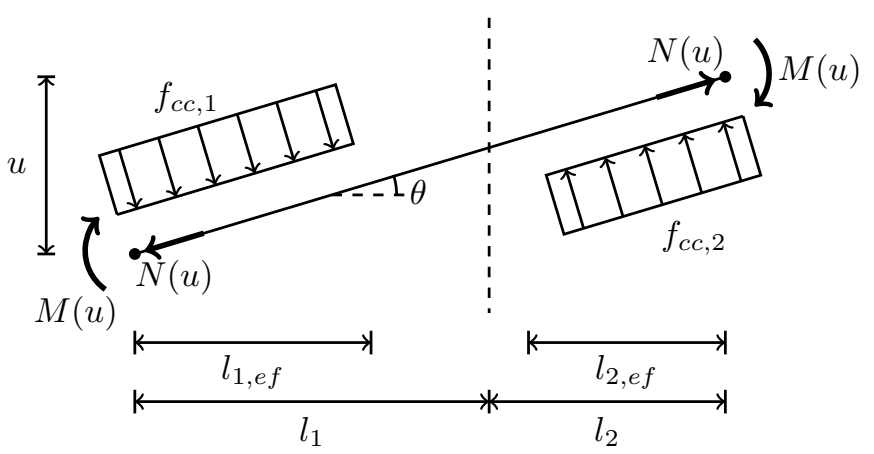

(b) Deformed state with distribution of contact pressure

Figure 7: Position of plastic hinges and extent of distribution of contact pressure at initiation of pure dowel action ( $a$ ) and at combined dowel action and catenary action (b) 


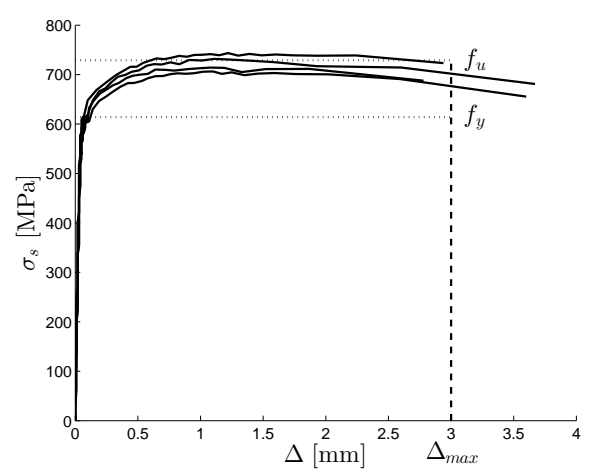

(a) Stress-elongation relation

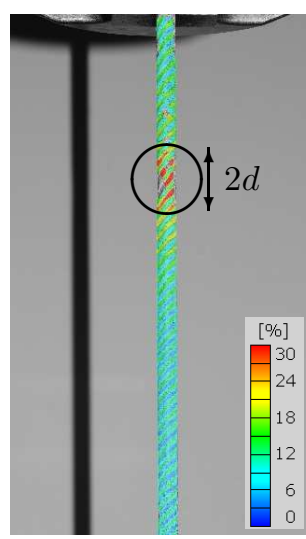

(b) Aramis results at necking (major principal strain)

Figure 8: Local stress-elongation relationship for rebars and indication of the measurement length spanning the zone where necking occurs 


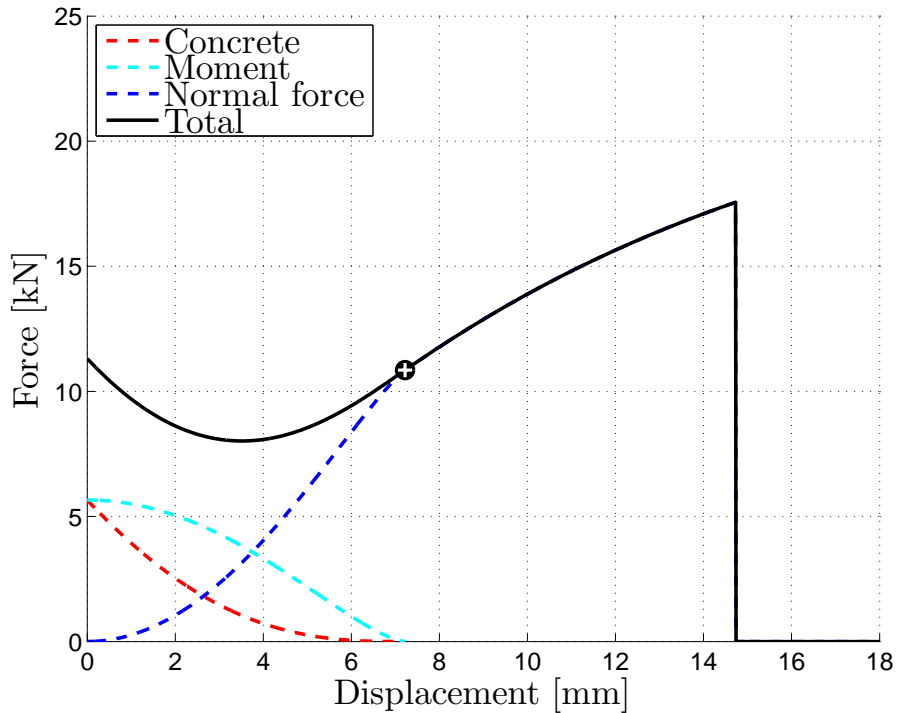

Figure 9: Load-displacement response of a single rebar crossing a frictionless joint 


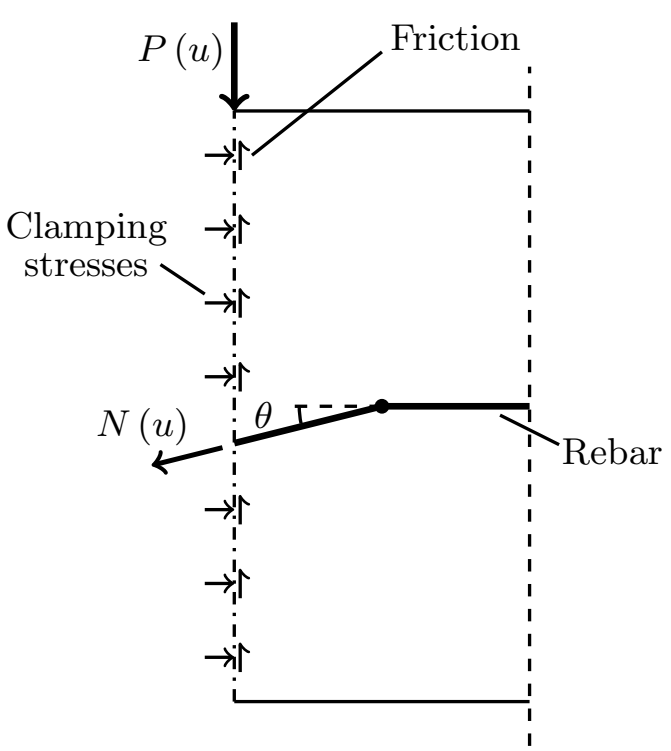

Figure 10: Contribution of friction in the interface 


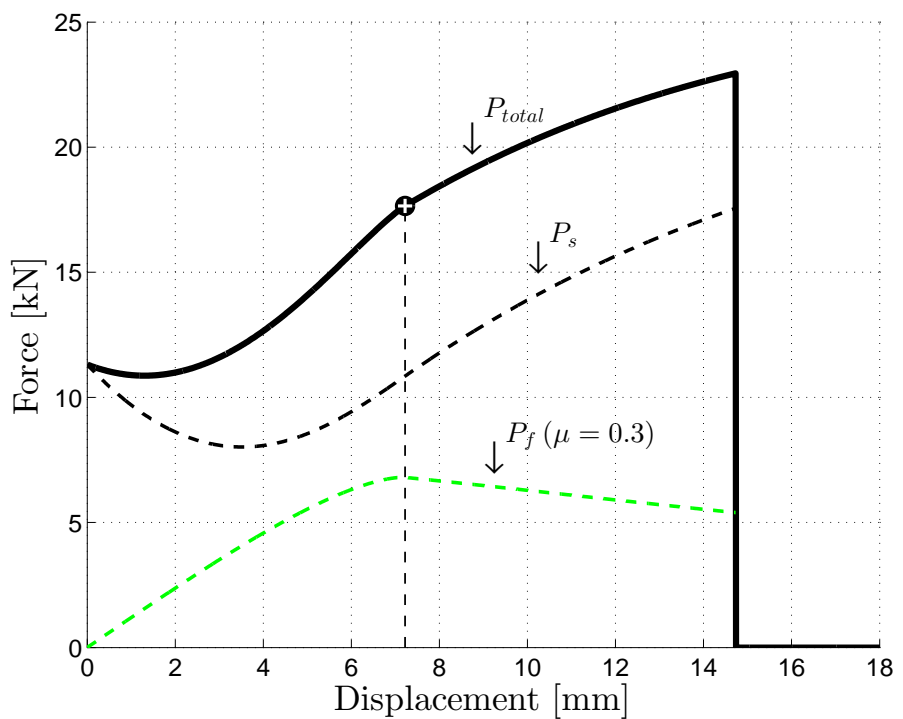

Figure 11: Inclusion of interface friction to the model response 


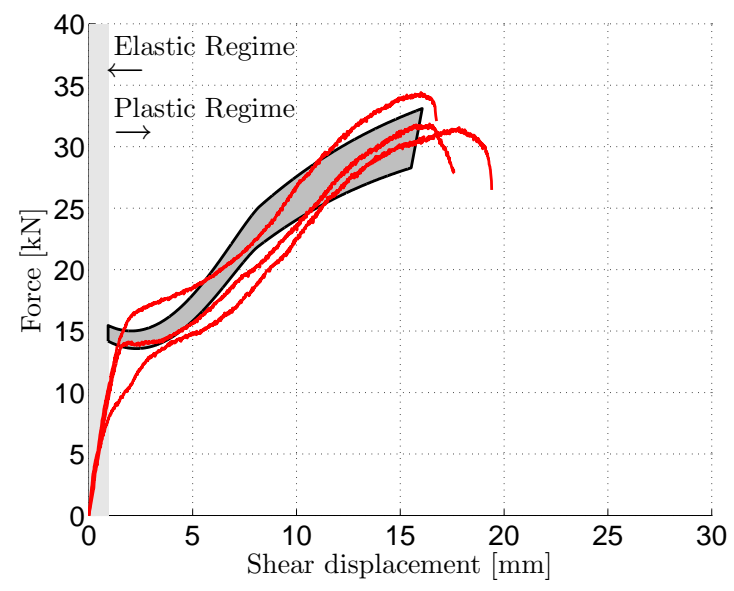

(a) $\mathrm{C} / \mathrm{C} 1$ rebar

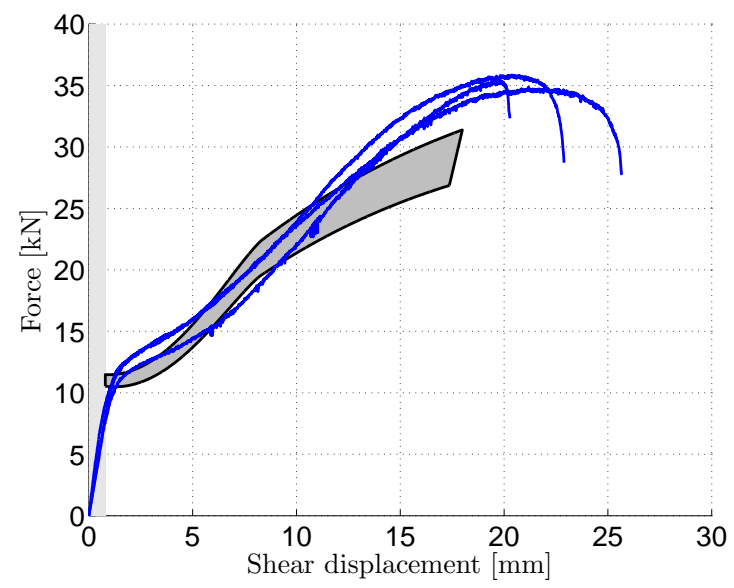

(b) M/M 1 rebar

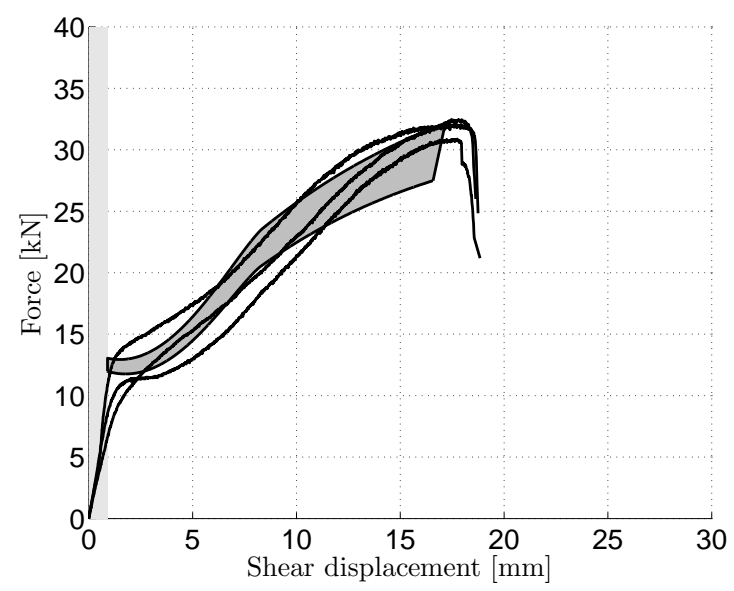

(c) M/C 1 rebar

38

Figure 12: Comparison of model with test results - 1 rebar 


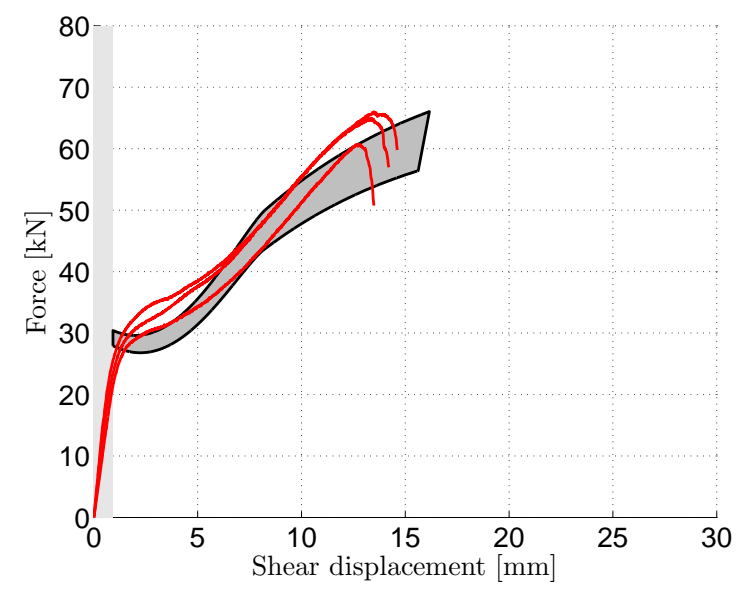

(a) C/C 2 rebars

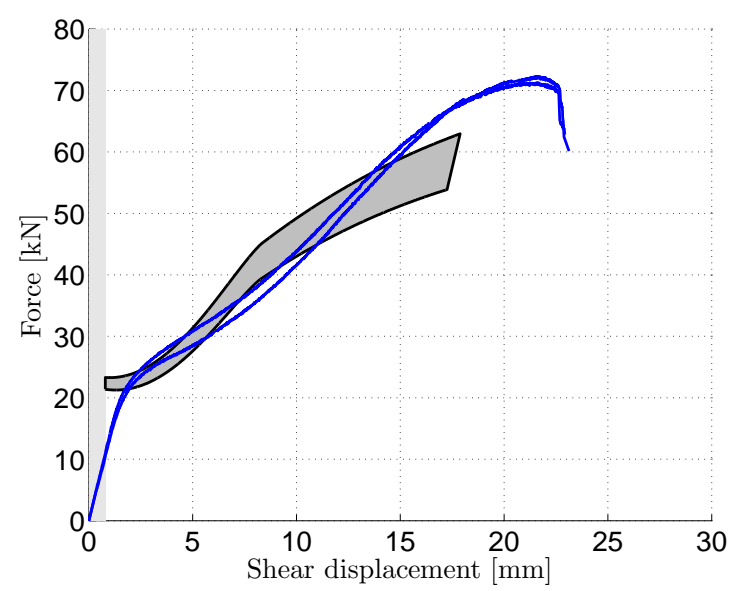

(b) M/M 2 rebars

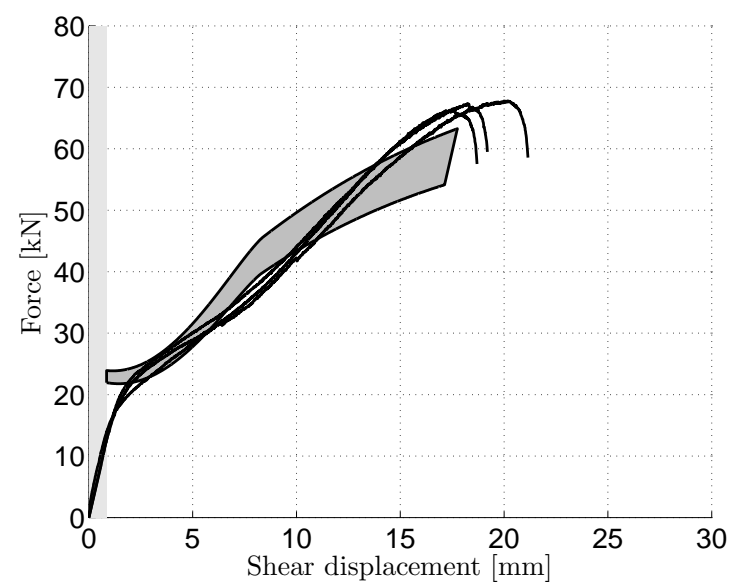

(c) M/C 2 rebars

39

Figure 13: Comparison of model with test results - 2 rebars 


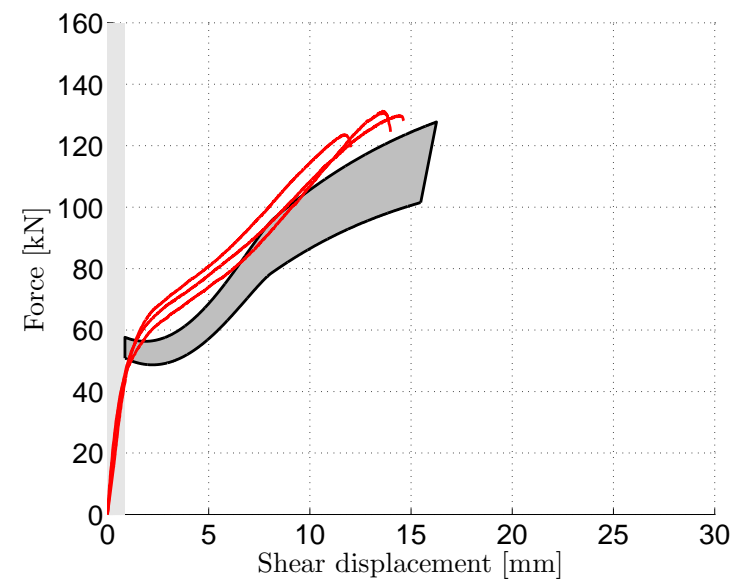

(a) C/C 4 rebars

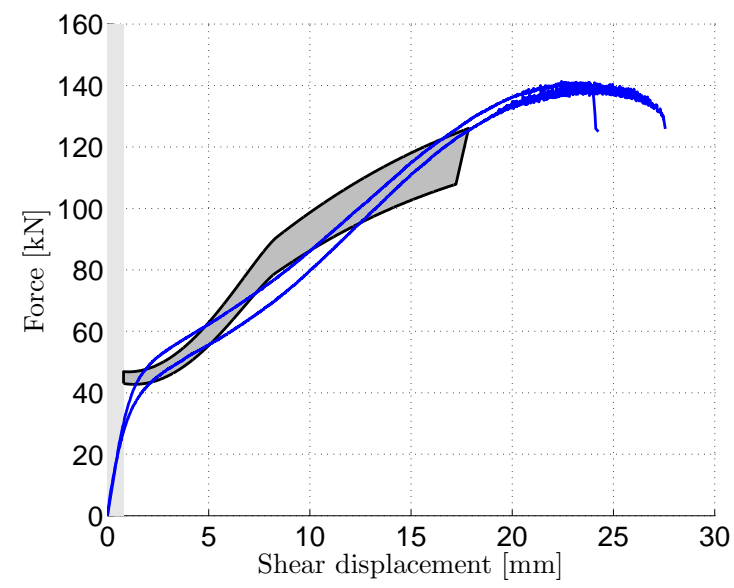

(b) M/M 4 rebars

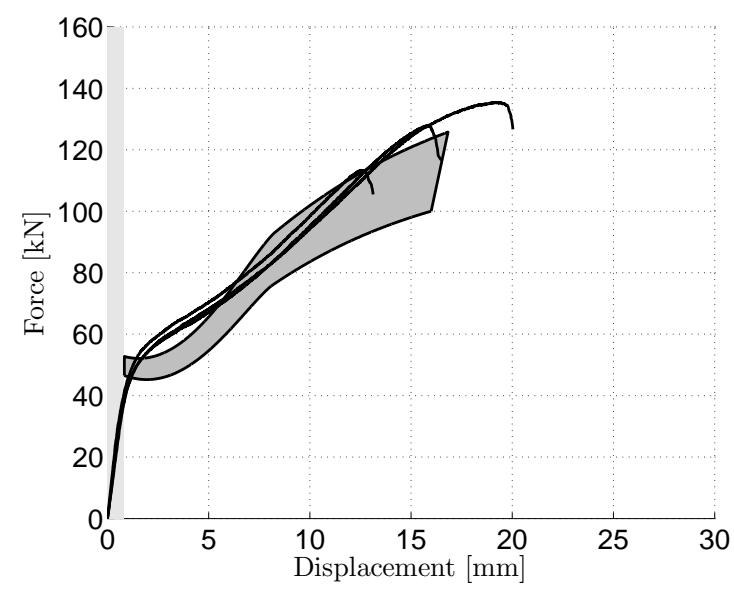

(c) M/C 4 rebars

40

Figure 14: Comparison of model with test results - 4 rebars 


\section{List of Tables}

1 Specifications and material properties for test series ( $C=$ concrete, $M=$ mortar, n=number of rebar 2 Proportions of the concrete mixture. . . . . . . . . . . . . . . . 43

3 Parameters used for presentation of load-displacement response for a single rebar crossing a frict 
Table 1: Specifications and material properties for test series ( $C=$ concrete, $M=$ mortar, $n=$ number of rebars)

\begin{tabular}{lccccccc}
\hline$n$ & Interface combination & $d[\mathrm{~mm}]$ & $f_{y}[\mathrm{Mpa}]$ & $f_{u}[\mathrm{MPa}]$ & $f_{c 1}[\mathrm{MPa}]$ & $f_{c 2}[\mathrm{MPa}]$ & Nos. of rep. \\
\hline 1 & $\mathrm{C} / \mathrm{C}$ & 8 & 614 & 729 & 48.0 & 48.0 & 3 \\
1 & $\mathrm{M} / \mathrm{M}$ & 8 & 614 & 729 & 33.1 & 33.1 & 3 \\
1 & $\mathrm{M} / \mathrm{C}$ & 8 & 614 & 729 & 33.3 & 47.7 & 3 \\
\hline 2 & $\mathrm{C} / \mathrm{C}$ & 8 & 614 & 729 & 46.5 & 46.5 & 3 \\
2 & $\mathrm{M} / \mathrm{M}$ & 8 & 614 & 729 & 34.1 & 34.1 & 2 \\
2 & $\mathrm{M} / \mathrm{C}$ & 8 & 614 & 729 & 30.3 & 35.3 & 3 \\
\hline 4 & $\mathrm{C} / \mathrm{C}$ & 8 & 551 & 708 & 43.0 & 43.0 & 3 \\
4 & $\mathrm{M} / \mathrm{M}$ & 8 & 614 & 729 & 34.5 & 34.5 & 2 \\
4 & $\mathrm{M} / \mathrm{C}$ & 8 & 551 & 708 & 37.2 & 45.4 & 3 \\
\hline
\end{tabular}


Table 2: Proportions of the concrete mixture

\begin{tabular}{lc}
\hline & {$\left[\mathrm{kg} / \mathrm{m}^{3}\right]$} \\
\hline Cement & 321.4 \\
Water & 156.1 \\
Superplasticizer & 2.0 \\
Aggr. 0-4 mm & 848.6 \\
Aggr. 4-8 mm & 330.0 \\
Aggr. 8-16 mm & 753.3 \\
\hline w/c & 0.49 \\
\hline
\end{tabular}


Table 3: Parameters used for presentation of load-displacement response for a single rebar crossing a frictionless interface

\begin{tabular}{lc}
\hline Parameter & Value \\
\hline$d$ & $8 \mathrm{~mm}$ \\
$f_{y}$ & $500 \mathrm{MPa}$ \\
$c_{1}$ & 5.0 \\
$f_{c, 1}$ & $30 \mathrm{MPa}$ \\
$c_{2}$ & 5.0 \\
$f_{c, 2}$ & $50 \mathrm{MPa}$ \\
$\Delta_{\max }$ & $3 \mathrm{~mm}$ \\
\hline
\end{tabular}




\section{Appendix A. Modeling of Elastic Displacement for Dowel Joints}

The elastic displacement can be estimated by the analogy of a beam on an elastic foundation [2-10]. By solving the fourth order differential equation, the maximum elastic displacement can be formulated as given in Ref. [4]:

$$
u_{0}=\frac{P_{0}}{2 \lambda^{3} E_{s} I_{s}}
$$

where $P_{0}$ is the maximum shear force (e.g. estimated by the load required to form plastic hinges, i.e. Equation (25a) with $u=0), E_{s}$ is the elastic modulus and $I_{s}$ is the second moment of area for the circular rebar. The parameter $\lambda$ expresses a stiffness per length and is given by [2]:

$$
\lambda=\sqrt[4]{\frac{k_{c} d}{4 E_{s} I_{s}}}
$$

where $k_{c}$ is the stiffness of the elastic foundation. For the concrete material a stiffness, $k_{c}$, is suggested by Soroushian [12]:

$$
k_{c}=\frac{127 \sqrt{f_{c}}}{d^{2 / 3}}
$$

